\title{
EL VIAJE TRIUNFAL DE CARLOS V POR SICILIA TRAS LA VICTORIA DE TÚNEZ
}

\author{
THE TRIUMPHANT JOURNEY OF CHARLES V THROUGH SICILY AFTER \\ THE VICTORY IN TUNISIA.
}

José Miguel Morales Folguera

Universidad de Málaga

ABSTRACT: In 1535 Emperor Charles $\mathrm{V}$ made a triumphant journey to the north of Sicily after the victory of Tunisia. The triumphal entries made in the Sicilian cities featured ceremonial elements which would later be imitated by the other Italian cities that received the Emperor. The Roman-style triumph and the chivalric romances are the main models used in the ephemeral decorations, which would have important consequences in European art of the period.

KEYWORDS: Charles V, Sicily, Tunisia, Triumphal Entries, Renaissance, Santa Cruz.

RESUMEN: En el año 1535 el emperador Carlos V realiza un viaje triunfal por el norte de Sicilia tras la victoria de Túnez. En las entradas realizadas en las ciudades sicilianas van a aparecer los elementos ceremoniales, que después van a imitar las restantes ciudades italianas, que van a recibir al emperador. El triunfo a la romana y las novelas de caballería son los principales modelos utilizados en las decoraciones efímeras, que van a tener importantes consecuencias artísticas en el arte Europeo de la época.

PALABRAS CLAVES: Carlos V, Sicilia, Túnez, entradas triunfales, Renacimiento, Santa Cruz. 


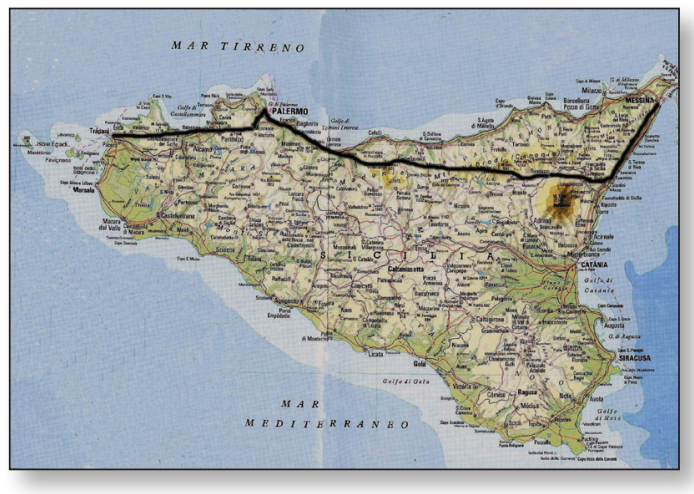

Fig. 1. Itinerario del viaje de Carlos V por el norte de Sicilia, realizado por el autor.

En el año 1975 André Chastel publica su estudio sobre las entradas de Carlos V en Italia (Chastel, 1975). Es la primera y más importante investigación a nivel internacional, que se ocupa de las dos estancias más festejadas de Carlos V en Italia. En 1530 en Bolonia para su doble coronación y en el bienio 1535-1536, cuando realiza su viaje triunfal por toda Italia tras la victoria de Túnez, que llevaría al emperador a visitar las ciudades sicilianas de Trapani, Monreale, Palermo, Termini Imerese, Nicosia, Randazzo, Taormina y Messina, y las italianas de Cosenza, Nápoles, Roma, Viterbo, Siena, Florencia y Luca [fig. 1].

Chastel pone de manifiesto cómo en las celebraciones organizadas por las ciudades italianas para recibir al emperador se reconstruye el triunfo a la romana, que después va a ser imitado en toda Europa e Hispanoamérica durante los siglos XVI, XVII y XVIII.

Doce años más tarde Fernando Checa (1987: 17-54) añade que el tipo de héroe en el que se inspira la imagen de Carlos V, configurada para las entradas triunfales por Italia, procede de las novelas de caballería y de los caballeros andantes, que también se remontan a la fundación de Roma por Rómulo [fig. 2].

Con posterioridad han ido apareciendo otros estudios que se han ocupado de

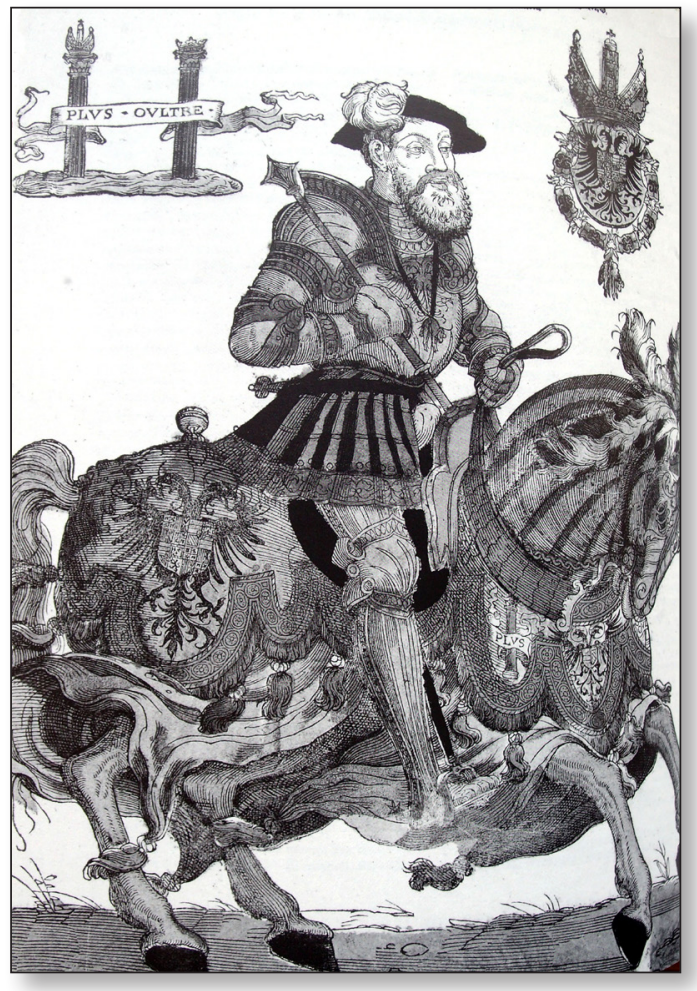

Fig. 2. Cornelis Anthonis Theunissen, Carlos $\mathrm{V}$ a caballo, 1547 ca. Grabado tomado de la obra de Agati.

analizar con distintos enfoques el viaje de Carlos V por Sicilia y la península italiana (Morales, 2014). En lo que respecta al antiguo reino de Sicilia los estudios recientes se han basado en la información facilitada por diversas crónicas coetáneas del siglo XVI (Mínguez, 2014). La más importante por su carácter general es la crónica manuscrita en dos volúmenes Memorie del regno dette del Duca d'Osuna, que fue publicada en el año 1929 por Vincenzo Castaldo en la revista Archivio Storico per la Sicilia Orientale.

También tiene un carácter general la obra del español Alonso de Santa Cruz, que describió de manera pormenorizada el viaje del emperador por toda Italia (Santa Cruz, 1922: III, IV, XII, 293-358). A pesar de su importancia está crónica es prácticamente desconocida por los investigadores italianos que se han ocupado del tema. 
Para la entrada en Messina, que es la que mejor conocemos y de la que se ha conservado más documentación, la obra más importante es la que publicó en el año 1535 Nicola Giacomo d'Alibrando (1535), que conocemos porque fue recogida en una publicación por Caio Domenico Gallo en el año 1758.

Otras crónicas posteriores, como la de V. Auria en 1690, G. E. Blasi en 1846, F. del Carretto en 1758 y los relatos inéditos del marqués de Villabianca (1720-1802) dan algunas noticias parciales pero muy precisas sobre los acontecimientos sicilianos.

El principal problema de las publicaciones realizadas sobre el tema es que están muy compartimentadas por países. La mayoría de las investigaciones son italianas y no tienen en cuenta las ediciones españolas. Un ejemplo claro es el caso del cronista español Alonso de Santa Cruz, que es totalmente obviado por la bibliografía italiana, a pesar de que su importancia es similar a la de Alibrando.

Por lo tanto en este trabajo se ha incorporado la bibliografía española al debate sobre el viaje de Carlos V por el norte de Sicilia, incluyendo las publicaciones realizadas en los últimos años tanto en Italia como en otros países europeos. Ello nos ha permitido llevar a cabo una lectura más pormenorizada de los programas iconográficos de las decoraciones efímeras erigidas con motivo de las entradas triunfales del emperador en las ciudades sicilianas.

\section{PRIMERA ETAPA DEL RECORRIDO TRIUNFAL: DE TRÁPANI A PALERMO}

La conquista de la Goleta representa «una etapa crucial en la construcción de la imagen imperial y heroica de Carlos V», quien a partir de ahora va a ser considerado como un general que dirige a su ejército a la batalla. De este modo no solo es equiparado con los grandes militares de la Antigüedad Clásica sino que los supera como soldado de Cristo (Viseglia, 2001a).

En las entradas realizadas en las principales ciudades del norte de Sicilia se pueden reconocer los elementos ceremoniales codificados, que se van a encontrar en los posteriores recibimientos realizados en la península italiana: recibimiento fuera de la ciudad; entrega de las llaves; reconocimiento de los privilegios ciudadanos; creación de arcos triunfales adornados con imágenes de la conquista de la Goleta, con héroes mitológicos y conquistadores romanos, utilizados como precedentes del emperador, que va a simbolizar los valores éticos del caballero cristiano, que después de la victoria restablece la paz, lo que va a producir el desarrollo de los súbditos del Imperio; y el uso de carros triunfales.

En este viaje triunfal el emperador iba acompañado por un gran séquito de miles de personas, formado por los cristianos liberados y los moros esclavizados, la guardia imperial formada por 3.000 soldados, y la corte que le solía acompañar en sus viajes, formada por el príncipe de Portugal, el maestro de la orden de Malta, el duque de Alba, el conde de Benavente, el duque de Medinaceli, el marqués de Aguilar, y los secretarios imperiales Granvela y Cobos (Viseglia, 2001b).

El 17 de agosto de 1535 la armada imperial abandona África llegando al puerto de Trápani después de tres días de un viaje tempestuoso y difícil por los vientos contrarios. Carlos V se va a hospedar en el palacio Chiaramonti, donde pudo descansar y reponerse de la batalla y del viaje. Durante su estancia el emperador hizo varias donaciones a las instituciones religiosas de Trápani. A la iglesia de San Nicolás una fuente de alabastro turquesa traída de África. A la parroquia de San Pedro un estandarte con brocados de oro. Y al convento de la Anunciata dos puertas de madera cubiertas de hierro y de procedencia tunecina. Por primera vez en su periplo jurará los privilegios urbanos en 


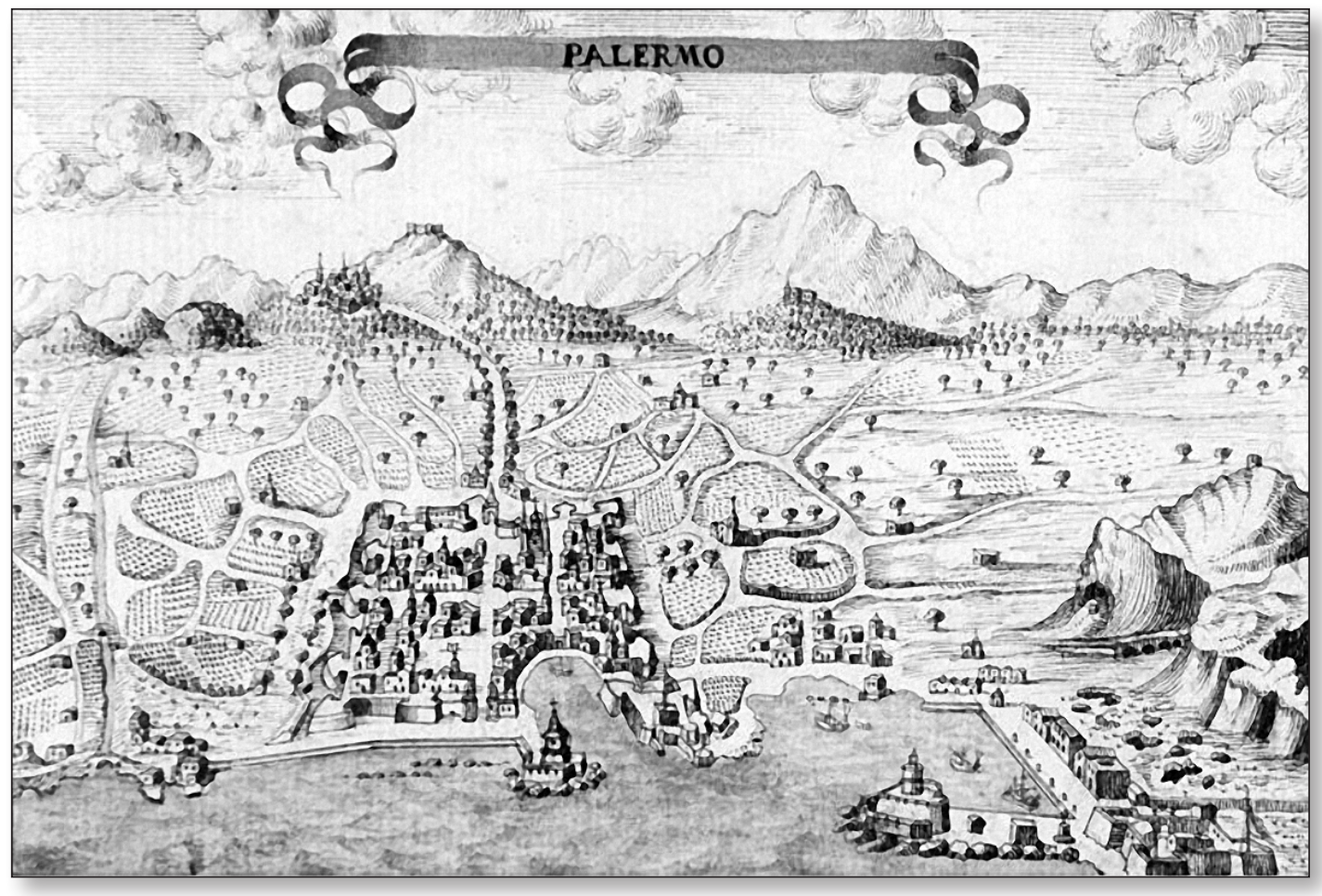

Fig. 3. Plano de Palermo, 1677, G. Merelli, Biblioteca Reale de Torino.

el duomo, conservándose un lápida de mármol en el Museo Pepoli, donde se recoge en latín dicho juramento (Castaldo, 1930: 89).

Después de una estancia de cuatro días en Trápani la comitiva imperial se dirigió a Palermo vía Alcano y Monreale, donde se hospedó unos días, mientras se terminaban los preparativos para la entrada, teniendo el emperador la posibilidad de admirar los mosaicos bizantinos de la catedral con uno de los mayores programas iconográficos de la Ciudad de Dios desde el Génesis hasta Pentecostés.

\section{LA ENTRADA TRIUNFAL EN PALERMO}

El 12 de septiembre el presidente del reino, Simone Ventimiglia con los magistrados y la nobleza de Palermo salieron de la ciudad para encontrarse con el emperador en el bosque de Partinico y para acompañarle en la entrada [fig. 3]. A su llegada a Palermo cuatro gentilhombres le hicieron entrega de un caballo de raza siciliana, todo cubierto de oro, ingresando por la Porta del Sole, llamada después Imperiale y actualmente Porta Nuova, ubicada junto al palacio de los Normandos [fig. 4]. Para esta ocasión se antepusieron a la puerta dos columnas con guirnaldas, trofeos y textos, en los que se ponía de manifiesto la grandeza del Imperio de Carlos con las palabras «Ab solis ortu usque ad occasum», que serán utilizadas con posterioridad como divisas por los reyes españoles (Agati, 2009: 127-128).

En el arco le esperaban las autoridades religiosas y civiles, cabalgando bajo palio hasta la catedral, donde junto al obispo de Mazzara entró en la iglesia, arrodillándose a rezar mientras se cantaba el Te Deum. Allí se le acercó el pretor de la ciudad, al que tam- 


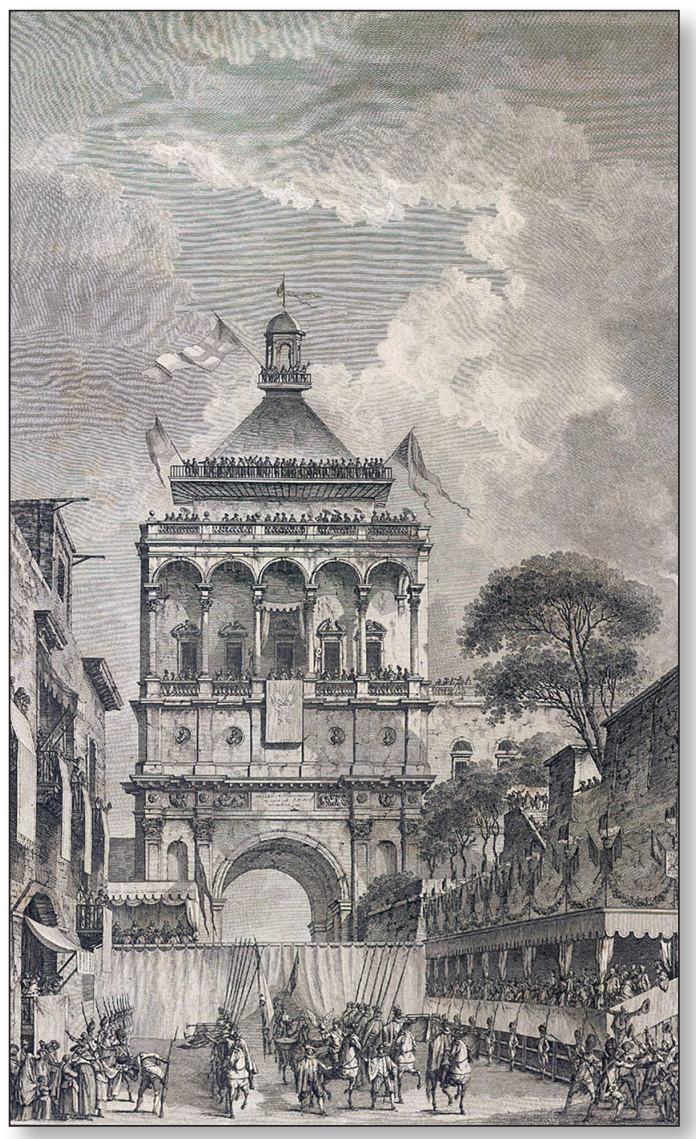

Fig. 4. Giostra celebrada delante de la Porta Nuova de Palermo, grabado tomado de la obra de Saint Non, R. de, Voyage pictoresque ou description de Royaume de Naples et de Sicile, Paris, 1781-1786.

bién llaman Sindaco, Guglielmo Spadafora, quien arrodillado a los pies del emperador, acompañado de muchos patricios y haciendo tres reverencias, le presentó al monarca los privilegios para que se comprometiera a respetarlos. Acabada la ceremonia el emperador salió de la catedral, subiendo de nuevo al caballo para continuar el recorrido hasta llegar a su lugar de residencia en el palacio de Ajutamicristo, el mayor banquero de la ciudad y banquero oficial del reino.

La recepción en Palermo se realizó a la manera de los triunfos romanos. El emperador iba precedido de los prisioneros esclavizados, seguidos por los cristianos liberados de la esclavitud musulmana, se dice que unos 20.000, la guarda imperial, la corte y unos 100 jóvenes que le esperaban junto a las autoridades civiles, militares y religiosas de la ciudad (Ligresti, 2006: 26-27).

Los habitantes de Palermo llenaron las calles para aclamar al emperador, decorando las fachadas de las casas con tapices y colgaduras. Tres arcos de triunfo se erigieron a lo largo del recorrido: en la calle del Cassaro, la calle principal de la ciudad con un trazado norte sur entre la entrada desde Monreale hasta el puerto, en la plaza de la Bocceria, el centro comercial, y en la Fieravecchia, junto a su residencia. El arco de la Bocceria era aislado e imitaba el mármol. Estaba adornado con escenas de la conquista de Túnez y la huida de Barbarrosa (Castaldo, 1930: 94). El arco que había al comienzo del Cassaro estaba coronado por una estatua del emperador victorioso. En el arco de Fieravecchia se destacaba la victoria como fundamento de la paz.

En la iglesia de la Pinta se conserva la única inscripción de estos arcos. Está realizada en latín y en ella se describe al invicto César, con cuyo triunfo en África había librado a Sicilia, Italia, España y otras islas del Mediterráneo de las incursiones de los musulmanes, estableciendo la paz. Auria (1690: 44) nos describe de la siguiente manera la entrada triunfal de Carlos V en Palermo:

En el año 1535 en el que llegó a Palermo la Cesárea Majestad del emperador Carlo Quinto triunfante en África y en Túnez, siendo pomposamente recibido pasando por un riquísimo puente, fabricado en el Molo, cuya grandeza tal vez en Roma no se vio obra más preciada, fue recibido por el Senado palermitano bajo un soberbio baldaquino de brocado de oro todo lleno de águilas, que sostenían los dorados bastones admirablemente decorados. A mano derecha en el primer lugar estaba el pretor de Palermo, Guglielmo Spadafora, y a la izquierda el capitán de justicia Pietro d'Afflitto. Con posterioridad pasó al palacio destinado a su alojamiento, hoy llamado d'Aiutami Cristo, noble y rica familia palermitana, junto a la puerta de Termin. 
Fagiolo y Madonna han manifestado que con su recorrido triunfal por Palermo desde la Porta Nuova hasta el palacio de Ajutamicristo Carlos V pretendía visitar los lugares más importantes de la ciudad: el centro político del Palacio Real, el centro religioso del duomo, y los espacios económicos y comerciales de la Bocceria, la Loggia y la Fiera Vecchia (Fagiolo, 1981: 122-125).

Durante los días de estancia en Palermo se organizaron varias giostras y torneos. Se realizaron luminarias y otras demostraciones de júbilo. Una de las giostras se desarrolló delante del palacio, donde se hospedaba, estableciéndose tres premios para los ganadores: el vencedor obtendría una cadena de oro, el segundo una gran taza de plata dorada y el tercero un cuenco con relieves repujados (Castaldo, 1930: 95). En torno a la plaza se colocaron suntuosos palcos para los más de mil caballeros ricamente vestidos (Mazzè, 1989: 72-73).

Los primeros días los pasó recibiendo los cumplimientos de los magistrados y embajadores de las principales ciudades del reino. Se le informó de la manera de hacer justicia, visitó los archivos públicos y la Real Chancillería, donde se colocó la inscripción: Silla di Carlo V.

El 16 de septiembre abrió el Parlamento en el Palazzo dello Steri o Chiaramonti, que concluiría el día 22 en el Palazzo de Ajutamicristo (Palmieri, 1856: 1235). Con este motivo se formuló un programa de restauración del orden y de la justicia, imponiendo la preeminencia del soberano, aunque manteniendo las prerrogativas jurídicas y constitucionales del Parlamento. El emperador también nombró como nuevo virrey a Ferrante Gonzaga, ligado por vínculos personales de fidelidad al soberano (Viseglia, 2001b: 101).

El discurso oficial de la apertura del Parlamento fue leído en lengua Toscana por el Protonotario del reino, Ludovico Sánchez, que hizo mención a la victoria del emperador y a los importantes beneficios que iba a traer para Sicilia. La respuesta en nombre de todo el reino fue realizada por el obispo de Patti en lengua Toscana, aunque con expresiones en siciliano, agradeciendo también los beneficios que se obtendrían de la victoria. Igualmente el Parlamento hizo una donación al emperador de $250.000 \mathrm{du}$ cados, que habían de ser pagados en cuatro meses por la iglesia (40.000), el municipio (80.000) y los aristócratas sicilianos (130.000).

El Parlamento pidió al emperador que el cargo de virrey fuera ocupado durante cuatro años, que los puestos internos fueran detentados por los habitantes del reino, y que se restituyeran los ingresos señalados por Alfonso el Magnánimo a la Universidad de Catania. Igualmente se pidió la eliminación de los bandidos de la isla así como los abusos de la administración de justicia (Agati, 2009: 129).

\section{CONSECUENCIAS POSTERIORES DE LA ESTANCIA DE CARLOS V EN PALERMO}

La estancia de unos días del emperador en Palermo iba a tener importantes consecuencias en el desarrollo urbanístico, arquitectónico y artístico de la ciudad. En primer lugar se nombró al arquitecto toscano G. B. Collepietra arquitecto del Senado y director de las grandes obras urbanas entre 1560 y 1602 (Fagiolo, 1981: 12).

Sofía di Fede (2005-2006: 103-118) ha señalado que esta estancia supone el punto de inicio del proceso de refundación urbana, dedicándose especial atención al recinto murado, que será rediseñado por el ingeniero bergamasco Antonio Ferramolino por orden del nuevo virrey Ferrante Gonzaga (1535-1546). Los virreyes españoles van a iniciar a partir de entonces la construcción de un nuevo palacio a espaldas del pala- 
cio de los Normandos, con una imponente y austera fachada mirando a la ciudad, delante de la cual se sitúa una gran plaza, adecuada para acoger, como en Nápoles, los grandes actos festivos promovidos por la corona y donde con el tiempo se va a erigir la monumental fuente de Felipe V (La Monica, 2007).

Este lugar privilegiado junto al palacio de los Virreyes, por donde el emperador ingresó en la ciudad viniendo desde Monreale, va a ser monumentalizado con la construcción de una gran puerta, en la que se van a colocar imágenes relacionadas con la victoria de Túnez, imponiéndose en este lugar clave una nueva imagen de Palermo. Fue Marc'Antonio Colonna (Civita Lavinia 1535-Medinaceli 1584), lugarteniente de Juan de Austria en la batalla de Lepanto y virrey de Sicilia desde 1577, quien imitará al monarca con su entrada triunfal en la ciudad el 24 de abril de ese mismo año. En el año 1584 Antonio Veneziano colocó una inscripción en el arco, en la que se destacaba al virrey como continuador de Carlos $\mathrm{V}$, venciendo a los turcos en Lepanto medio siglo después de la gesta de Túnez.

La nueva puerta se construye como un monumento a la memoria del triunfo de Túnez por el emperador. La puerta tiene dos frentes diferentes, aunque unificados por las logias y la pirámide superior. El frente interno es de estilo clasicista y el externo de estilo rústico, con la inclusión de cuatro figuras estipitescas, dos con los brazos cortados y las otras dos con los brazos cruzados sobre el pecho, que representan a los esclavos musulmanes que acompañaban al emperador en su cortejo triunfal. Todo ello se remata con un ático con los escudos del monarca, del virrey y de la ciudad [fig. 5].

La Porta Nuova se construye como una contaminación arquitectónica de los modelos de la torre, del belvedere, del arco de triunfo y del monumento celebrativo (Fagiolo, 1981: 42-43). Su modelo es la Porta Pía de Roma, y junto con la Porta Felice

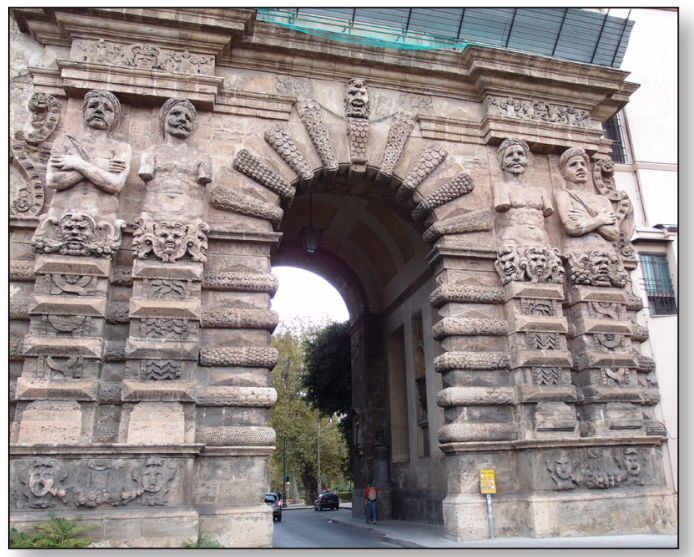

Fig. 5. Arco de la Porta Nuova de Palermo, Fachada exterior. Foto del autor.

en el otro extremo del Cassaro al lado del puerto, simbolizan «las dos columnas de Hércules...la una mirando a Europa, la otra a África en dirección a Túnez».

En el año 1631 se va a erigir a mediación del Cassaro, en la Piaza Bologni, un monumento que representa al emperador en el momento de jurar las leyes de Sicilia. Consta de un alto basamento en piedra decorado con relieves e inscripciones, alusivos a la creación de la obra, emblemas del emperador, como el águila bicéfala y la corona imperial con las columnas de Hércules y el Plus Ultra, trofeos de armas, y un gran dragón de siete cabezas, símbolo de los enemigos vencidos. En lo alto se halla la estatua en bronce de Carlos V, obra del escultor Scipione Li Volsi. El emperador se halla de pie vestido a la romana, apoyando el cuerpo sobre la pierna derecha mientras descansa la izquierda. Con la mano izquierda sostiene la punta del bastón, en un gesto de indiferencia, mientras que adelanta la derecha, abierta en el momento de jurar los privilegios [fig. 6].

Algunos edificios construidos en Palermo a partir de 1535 van a recordar las decoraciones de carácter efímero realizadas con motivo de la entrada del emperador, diseñando una "nuova architettura all'antica». 


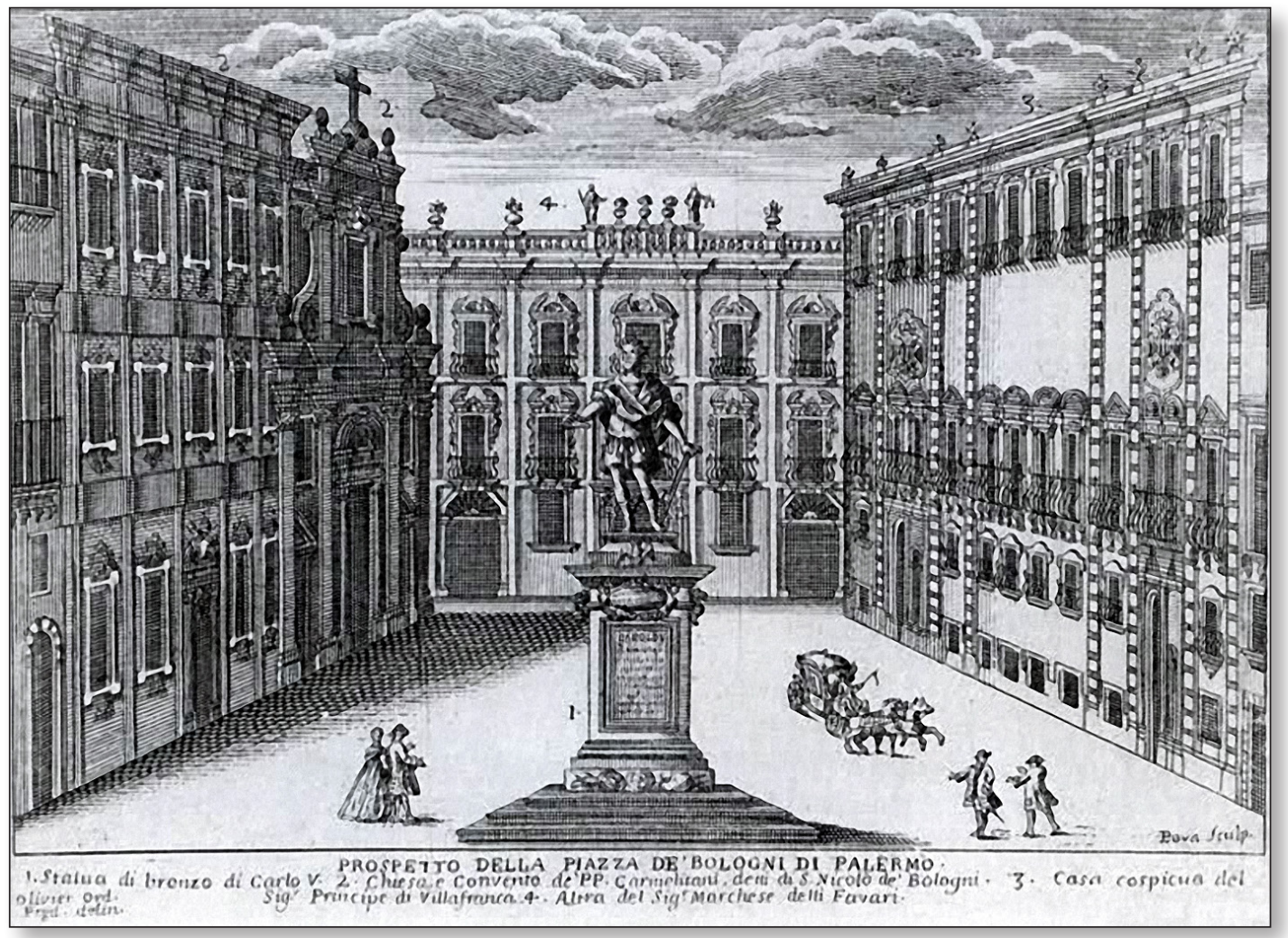

Fig. 6. Grabado de la Piazza Bologni de Palermo con el monumento de Carlos V, siglo XVIII.

Es el caso del proyecto de Santa Eulalia de los Catalanes, que recuerda el grabado del Templum Pilati (c. 1475-1485), en el que aparece una gran logia de tres arcos y tondos con bustos en la zona superior (Hittorf, 1935). El tímpano del arco central está cerrado para acoger el escudo imperial con las columnas de Hércules y el águila bicéfala (Nobile y Scaduto, 2005-2006: 16-21). En ese lugar se colocó el arco de la Bocceria en honor de Carlos V. Así mismo la Vía Argenteria se decoró con telones, tapices y estructuras efímeras a la antigua.

\section{LA SEGUNDA ETAPA: EL CAMINO DE PALERMO A MESSINA}

El 14 de octubre el emperador salió de Palermo, llegando inicialmente a Termoli, actual Termini Imerese, famosa por sus baños de agua caliente. La siguiente mañana pasó por Polizzi y el 16 entró en Nicosia, donde se alojó en el palacio del Regio Milite Gian Filippo la Via. En su iglesia hay una cátedra de madera llamada de Carlos V, en la que se ve en el respaldo un medallón con la imagen del emperador y el texto: Sacellum hoc in quo sedit $V$ Carolus Romanorum Imperator in ipsius honore extruxit civitas Constanti.ma quod vetustote deruptum refici curarum spet. Joannes Georgius Alessius Hetor La Porta Bartholomeus 
di Bartolo et Jonnas Vincentius Barone Iurati an. dom. 1644 (Agati, 2009: 130).

El día 17 llegó a Troina, siendo recibido el mismo día a tres kilómetros de la ciudad de Randazzo por la nobleza y el Civico Magistrato, que le entregó las llaves de la ciudad en una taza de plata. Entró en la ciudad por la puerta de San Martino sobre un caballo blanco, acompañado por su séquito, soldados españoles y alemanes, y una cadena de prisioneros moros. Atravesó varios arcos de triunfo hasta el Palacio Real, donde pernoctó (Agati, 2009: 131).

Mario Mandalari ${ }^{1}$ afirma que el emperador pernoctó en Randazzo la noche del día 17, partiendo la mañana del día 18 hacia Taormina, y por la carretera de San Alessio se dirigió a Messina, siendo aclamado a su paso por todos los vecinos hasta el convento de San Plácido, donde pasó la noche (Castaldo, 1930: 98).

\section{LA ENTRADA TRIUNFAL EN MESSINA}

De todo el viaje triunfal de Carlos $\mathrm{V}$ por Sicilia y la península italiana la entrada en Messina es la que está mejor documentada, ya que existen varias crónicas italianas y una española, y se conservan los dibujos de las construcciones de arte efímero realizadas por el pintor Polidoro da Caravaggio. Se hallan en un museo de Berlín y están agrupados en un álbum de 126 folios con el título Disegni i Studio di Polidoro da Caravaggio fatti in Roma e in Messina. ${ }^{2}$ Los dibujos están hechos a pluma y tinta marrón, algunos parecen estudios terminados y tienen mayor precisión, y otros son simplemente esquemas, apuntes e ideas repetidas (Castris, 2001: 133).
La crónica italiana más importante sobre la entrada en Mesina fue la realizada en 1535 por el sacerdote Nicolo Giacomo d'Alibrando (1535), que conocemos gracias a la reproducción llevada a cabo por Caio Domenico Gallo en 1758 (Capraro, 20072008).

Menos conocida, sobre todo entre los investigadores italianos que han investigado sobre el tema, aunque no menos importante, es la crónica de Alonso de Santa Cruz, cosmógrafo e historiador español del Renacimiento, que redactó entre 1550 y 1552 la Crónica del emperador Carlos $V$, que fue publicada en el año 1922 (Santa Cruz, 1922: 293-358). En el volumen 2, capítulo XII, se recoge el viaje de Carlos V por Sicilia e Italia después del triunfo de Túnez, dedicando especial atención al recibimiento en Messina, que por su extensión y por los numerosos datos que aporta puede compararse con la crónica de Alibrando.

Fue el senado messinés el que comisionó la realización de las obras arquitectónicas, pictóricas y festivas a diversos artistas y humanistas presentes en la ciudad. En su realización participaron el pintor Polidoro da Caravaggio, el arquitecto Domenico Carrara, y los miembros de la academia messinesa Maurolico, Villadicani, Tommaso e Pietro Faraone, Baldo di Granati y Bartolomeo Perrone, que fueron los autores del programa iconográfico y festivo (Giorgianni, 1996: 191-193). Algunos de los temas decorativos y simbólicos fueron utilizados con posterioridad por Vanello en la fuente de Orión, ubicada junto a la catedral, y por Montorsoli en la fuente de Neptuno, situada en la zona del puerto, así como en la fiesta de la Assunta. Maurolico jugó un papel fundamental en la elaboración del programa iconográfico y en la realización técnica de los aparatos festivos: arcos de triunfo, carros, trofeos y textos.

1. Mandalari, M. [1901]. Ricordi di Sicilia: Randazzo, Cittá di Castello. Tomado de Agati (2009: 131).

2. El álbum con los dibujos de Polidoro da Caravaggio se encuentran en el Staatliche Museen de Berlín.

IMAGO, NÚM. 7, 2015, 97-III 


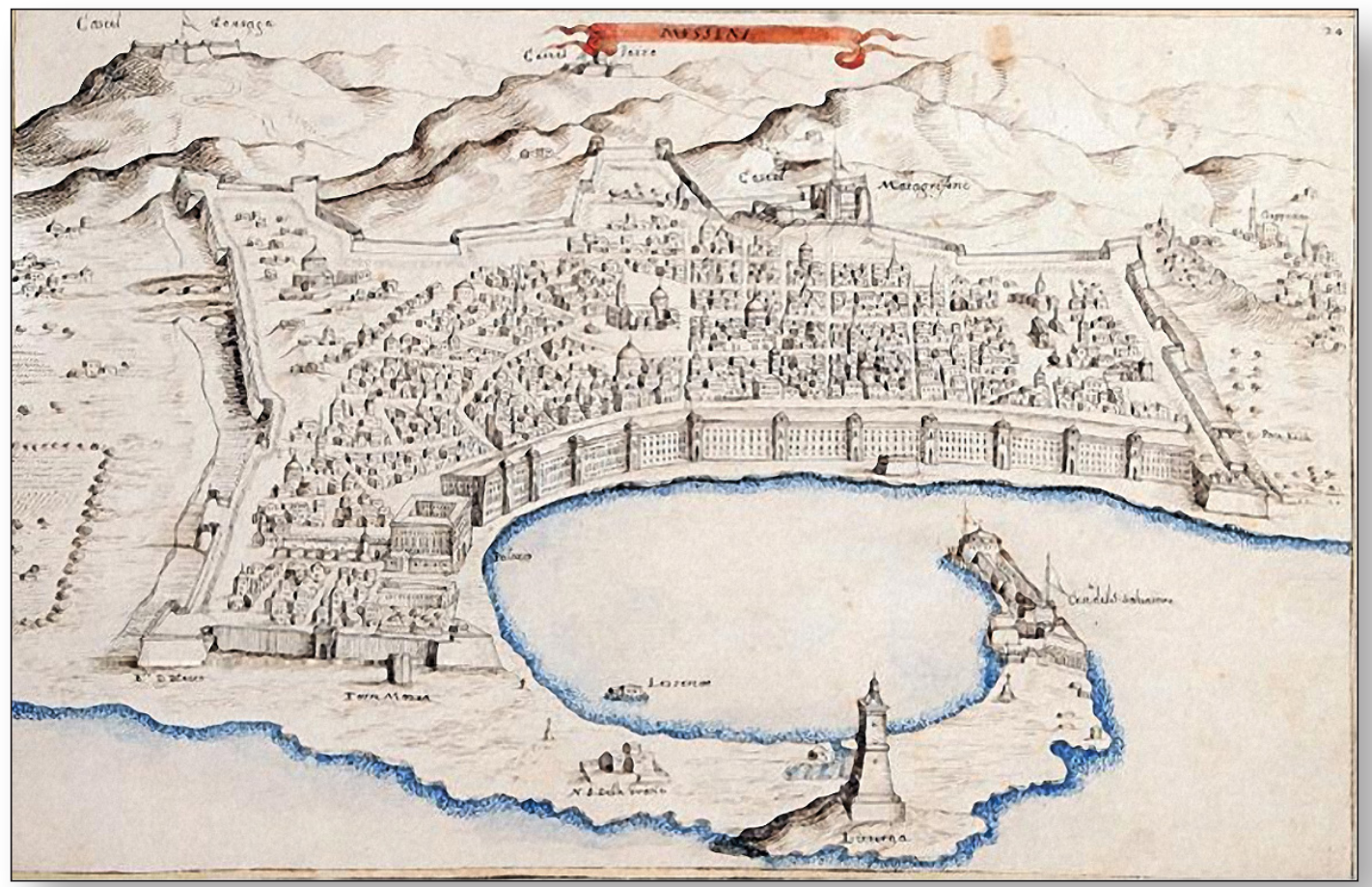

Fig. 7. Plano de Messina, 1677, G. Merelli. Biblioteca Francisco de Zabálburu, Madrid.

El día 21 de octubre Carlos V hace su entrada triunfal en la ciudad del estrecho por la Vía del Dromo, que era una calle plana con ocho millas de largo, donde fue recibido por 400 jóvenes, soldados de a pie ricamente vestidos, el arzobispo con el clero vestido de pontifical, el archimadrita Spataforo con su abad, multitud de personas del pueblo, teniendo como fondo el sonido de la artillería. La ciudad le entregó un caballo bellamente adornado, al que su majestad se subió acompañado de seis jurados, que sostenían las astas con un palio dorado bordado. Cuando el emperador se encontró con el arzobispo, se bajó del caballo y se quitó el gorro para besar la cruz [fig. 7]. Sobre un estrado el conde Condoiani, el síndico y un elegido por la ciudad le presentaron las llaves y los privilegios para que el emperador se comprometiera a mantenerlos [Castaldo, 1930: 99-100].

Santa Cruz indica que este camino estaba adornado como una vía triunfal con cinco arcos de triunfo, describiendo inicialmente los tres ubicados al comienzo del recorrido: «el primero de yedra, el segundo de olivo y el tercero de laurel, hechos rústicamente en señal de concordia, paz y victoria» y consagrados respectivamente a la Concordia, a Hércules y a la Victoria (Santa Cruz, 1922: 295). Alibrando (1935), por su parte, da indicaciones más precisas, señalando también que fueron cinco los arcos construidos.

El primer arco tenía seis columnas adornadas de laurel, en lo alto había una Victoria alada vestida de rojo, portando en la mano derecha una corona de laurel, y bajo la cornisa se veían las siguientes palabras escritas en oro «Vittoria, Augusti». El segundo arco estaba adornado de roble y en el centro de la parte superior tenía un Hércules y en el friso se veían las palabras «Fortitudo Augusti». El tercer arco estaba adornado de hiedra, tenía la figura de una Concordia en lo alto y las palabras en oro decían «Concordia Augusti». El cuarto arco estaba 
adornado de olivo y en lo alto tenía la imagen de Minerva con un ramo de olivo en la mano, y debajo las palabras "Pax Augusti». Y el quinto arco, situado en la entrada del río Cammari, que se halla a media milla de la ciudad, tenía un diseño cuadrifonte, cuyos cuatro frentes representaban las cuatro estaciones del año. El primer pórtico representaba la Primavera, el segundo repleto de frutos el Otoño, el tercero el Invierno y el cuarto el Verano. Encima de cada pórtico se podían ver las palabras «VER, ESTAS, AUTUNNUS, HIEMS", y en la parte superior las armas del emperador y en los extremos las armas de la ciudad.

Cuando el emperador llegó a un tiro de piedra de la Puerta de San Antonio se encontró delante un soberbio arco de triunfo diseñado por Polidoro da Caravaggio [fig. 8]. Tenía un palmo de basamento, 35 palmos de alto, 18 columnas dispuestas en tres hileras de profundidad, con seis en cada frente alrededor de un arco central, e imitaba el mármol. Encima de los pórticos se encontraban dos victorias, que sostenían con una mano las armas del emperador y con la otra una palma. En los lados se situaban las armas de la ciudad sostenidas por putti desnudos. En ambas fachadas se dispusieron varios textos escritos en letras de oro, que ensalzaban la figura del emperador como soldado victorioso en África y como restaurador de la paz.

Uno de los textos decía «Al emperador César Carlos V Augusto, conservador de la república cristiana, el Senado y el pueblo de Mesina por el vencimiento de África, lo dedica». Encima había cuatro versos en latín, dos en cada frente. En el frente externo se veía el siguiente texto: “¡Oh Europa! El Emperador guerrea para ti; poco ha fue sojuzgada África y ahora tiembla la gran Asia; los que el tiempo pasado venció y domó Roma en tres guerras y en muchos años, en un solo mes venció y domó el Emperador

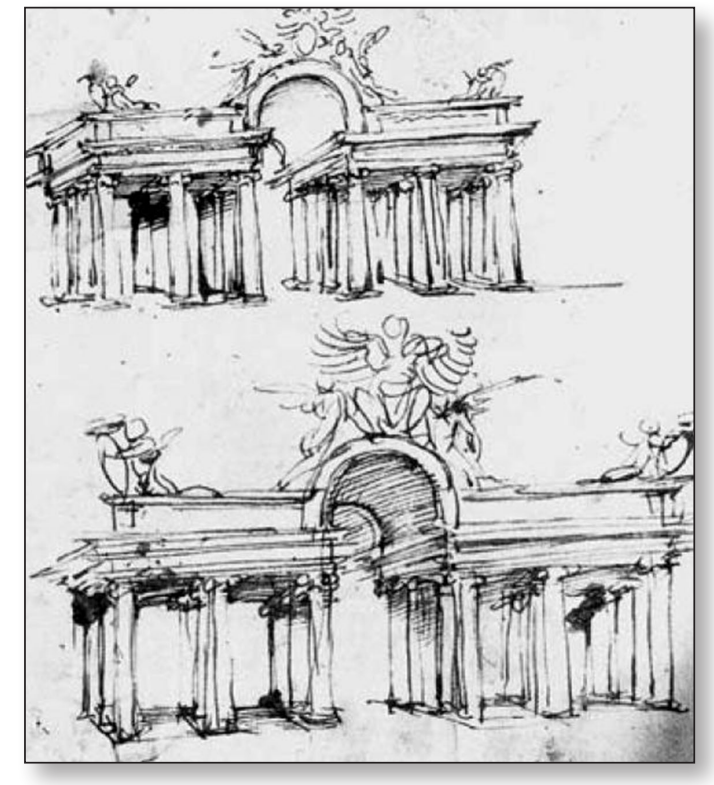

Fig. 8. Arco de la Puerta de San Antonio de Messina, Polidoro da Caravaggio, Staatliche Museen de Berlín.

Carlos». En el frente interior hacia la ciudad se veía el siguiente escrito: "Al divino Emperador Carlos $\mathrm{V}$ máximo e invencible, por la paz restituida y el Imperio extendido y aumentado, pusieron este arco de Mesina» (Santa Cruz, 1922: 296-297).

Sobre la puerta de San Antonio se había erigido otro arco de triunfo de piedra falsa, con dos columnas y dos pilastras, arquitrabe, friso y cornisa. Sobre el frontispicio había una escultura de la Fama alada en mármol con dos trompetas en la boca en el momento de hacerlas sonar, dos braceros en los lados con llamas de fuego, trofeos conseguidos en la toma de la Goleta en los frisos, y en el arquitrabe un texto con las letras doradas: " "A solis ortu ad occasum» (Catris, 2001:132). Los textos son atribuidos al sacerdote y matemático Francesco Maurolico (Alibrando, 1535: 506).

El cortejo de su Majestad hacia la catedral transcurrió por la Strada Maggiore, llegando al plano de San Juan junto a la iglesia

3. El texto es parecido al colocado en la Porta Nuova de Palermo a la entrada de Carlos V.

IMAGO, NÚM. 7, 2015, 97-III 
del priorato, donde había dos fuentes. Una era de "pietra macchiata di tauromina", en cuyo interior se veía un delfín echando agua por la boca, detrás Arión en mármol con la lira en la mano, y en el otro lado una sirena de mármol con una serpiente entre las manos, que aludía al tránsito por el estrecho de Messina por los peligrosos acantilados de Escila y Caribdis.

La otra fuente era también de mármol y redonda. Estaba llena de agua y se adornaba con leones, que echaban agua por sus bocas. En lo alto había una mujer, que representaba a la ciudad de Messina. Tenía el escudo con las armas reales en el pecho, y bajo la guirnalda de la frente se leían las siguientes palabras esculpidas en el mármol: «El Senado y pueblo romano, vencido Herión, me estatuyó cabeza de Sicilia y que me ensalce con título de nobleza y usase de poder romano». ${ }^{4}$ En el recorrido hasta la catedral el emperador estuvo acompañado por dos carros triunfales, uno pequeño y otro grande.

El carro grande tenía 50 palmos de altura, iba sobre cuatro ruedas y estaba estructurado en tres cuerpos. El primero estaba decorado con trofeos, victorias, pirámides, escudos imperiales en sus frentes y las cuatro virtudes cardinales en las esquinas. En el segundo cuerpo había dos ruedas con cuatro niños alados en cada una y la representación pintada de un carro de oro en una de las ruedas y de un dragón en la otra con la osa mayor y la osa menor, y encima la bola del mundo con seis niños, que llevaban ramos de olivo en las manos. Sobre la bola del mundo se hallaba la figura del emperador con armadura, la corona imperial y una Victoria en la mano derecha (Santa Cruz, 1922: 297).
El carro pequeño era llevado por seis moros y constaba de un pequeño altar triangular, sobre el que había un trofeo formado por un arnés a la antigua con su yelmo, escudo, arco y carcaj. En la parte delantera del carro se veía el siguiente texto: «La paz reina so tu guía y la justicia tornó a la tierra; pon tú, padre de la patria, dos trofeos a Júpiter». Debajo de los versos se habían pintado un ramo de olivo y una espada. En la parte posterior del carro se colocaron los siguientes versos: "Roma, temiendo el tiempo pasado a Cartago, la destruyó y puso por el suelo, y ahora restituida en sí sufre el yugo del invencible Emperador». Debajo se había pintado un yugo junto a la base triangular del trofeo con el siguiente texto: «El divino Emperador Carlos, vencida África, puso trofeo" (Alibrando, 1535: 508-509).

Cuando el emperador llegó a la catedral se organizó un espectáculo, que recordaba dramas religiosos medievales de otras zonas del Mediterráneo, lo que introduce un tema cristiano en el predominante contexto pagano de la entrada. Este esquema teatral también se inspira en tradiciones religiosas y profanas que se van a desarrollar en Messina a partir de 1535, y que recuerdan otras celebraciones más antiguas como el Misterio de Elche en España, que se organiza al menos desde el 15 de agosto de 1266, y la fiesta de la Asunción de Messina, que se remonta igualmente a finales del siglo XIII (Giorgianni, 1995: 249-294).

Sobre la puerta de la catedral se había representado un cielo con nubes, de donde fue bajando un coro de 24 ángeles, que descendían de cuatro en cuatro, recogiendo los últimos el trofeo del carro triunfal para llevarlo de nuevo hasta el cielo de nubes.

Tras apearse del caballo Carlos V entró en la catedral por la puerta principal, que es-

4. Arión, natural de la isla de Lesbos, fue un gran músico que, cuando volvió muy rico a su tierra con lo que había ganado con su arte, los marineros por quitarle sus riquezas le quisieron echar al mar. Él les pidió que le dejasen tocar la lira y que después le matasen. Cuando estaba tocando su instrumento se tiró al mar, siendo recogido por un delfín, que le llevó hasta Laconia (Lacedemonia) en el Peloponeso, por lo cual el delfín fue catasterizado en una estrella. Herión fue un tirano de Sicilia, al que vencieron los romanos. 
taba adornada con dos columnas coronadas por dos cabezas antiguas de mármol, que representaban a Escipión el Africano y a Aníbal. Escipión decía así en dos versos: «Den la ventaja los romanos, dela también mi gloria y fama, porque un poderoso Capitán en armas doma súbitamente todo lo soberbio». Aníbal tenía también sendos versos, en los que parecía que se maravillaba preguntando así: "¿Qué esfuerzo de Capitán es éste, qué piedad tan grande que tan de repente poco ha quitado a los míos sus Reinos y se les dio?» (Santa Cruz, 1922: 299).

El emperador se dirigió a un sitial delante del altar, donde oró durante unos minutos, siendo bendecido por el arzobispo. Con posterioridad salió del templo y volvió a subirse al caballo para dirigirse a su lugar de residencia en el Palacio Real, delante del cual había otro arco de triunfo, que imitaba el mármol blanco, con dos columnas en cada frente, dos ángeles en la parte superior y numerosas inscripciones en clave romana, alusivas a la victoria de África, a la paz restituida y al Imperio extendido, llamando a Carlos "el divino», "Emperador Augusto», "Conservador de la República Cristiana» y «Africano» (Castaldo, 1930: 101-103; Santa Cruz, 1922: 301; Alibrando, 1935: 506-513).

Según Alibrando en el puente de la Dogana se erigió un nuevo arco de triunfo, que fue visitado por el emperador a pie desde el Palacio Real a su salida de la ciudad [fig. 9]. Se conserva un dibujo de Polidoro da Caravaggio de dicho arco con unas dimensiones de 169 x 137 mm. en el Staatliche Museen de Berlín. En el dibujo se observa que el arco tenía cuatro columnas, dos en cada frente, era de piedra "miscia», y poseía capiteles, arquitrabe, friso y cornisa, donde se habían colocado diversas figuras de divinidades marítimas. El arco tenía dos basamentos laterales, sobre los que se habían representado varias figuras de tritones, y en lo alto del arquitrabe se hallaba el carro de Neptuno con otros tritones (Castris, 2001 :135).

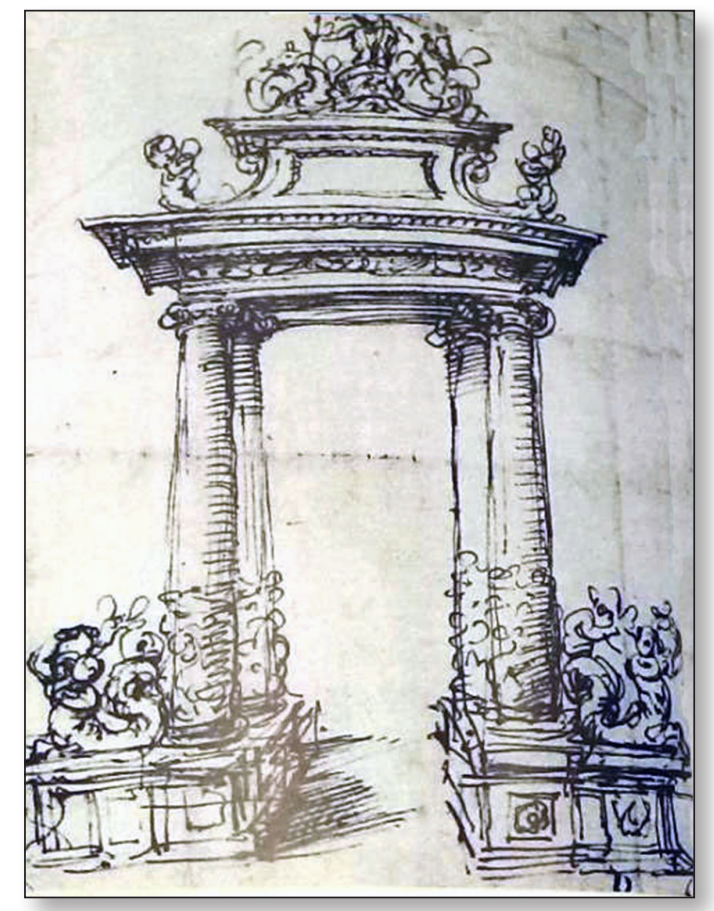

Fig. 9. Arco de la Dogana de Messina, Polidoro da Caravaggio, Staatliche Museen de Berlín.

Entre el gran número de dibujos conservados y atribuidos a Polidoro figura también un edículo arquitectónico con el escudo imperial y el de la ciudad de Messina, que se puede asociar con alguno de los aparatos triunfales construidos en 1535 [fig. 10]. Castris lo relaciona con alguna máquina destinada a decorar el interior de la iglesia o cerrar la perspectiva de alguna calle (Castris, 2001 :136).

Con motivo de la llegada del emperador la ciudad organizó tres días seguidos de luminarias nocturnas, fuegos artificiales y cabalgatas por toda la urbe, mientras que el pueblo gritaba "Imperio, Imperio».

El domingo siguiente regresó Carlos V a la catedral a caballo para asistir a la misa celebrada por el arzobispo. Tras el credo se organizó un espectáculo pirotécnico en medio de la iglesia, que representaba el primer testimonio de máquina destinada a la destrucción, que recuerda a las máqui- 


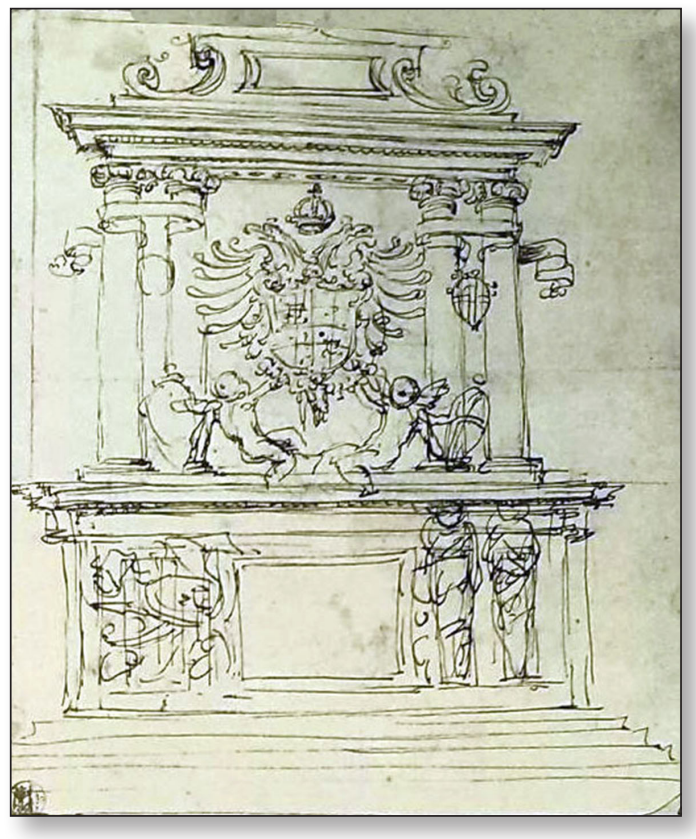

Fig. 10. Edículo arquitectónico con el escudo imperial, Polidoro da Caravaggio, Staatliche Museen de Berlín.

nas renacentistas construidas en Ferrara y en Siena entre finales del 400 y comienzos del 500. Inspirándose en el asedio de Túnez, se representó una ciudad con las armas del turco, que era incendiada por un águila bicéfala que le enviaba todo tipo de rayos hasta arruinarla completamente, surgiendo entonces en ese lugar una cruz. Polidoro da Caravaggio realizó los diseños de los aparatos, mientras que la ejecución material fue llevada a cabo por el arquitecto Domenico Carrara [Augello y Guarneri, 1996, 20]. De este modo la victoria de Túnez recordaba la conquista de Cartago y anunciaba la conquista cristiana de Constantinopla. Por eso a la entrada de la catedral se habían colocado los bustos de Escipión el Africano y de Aníbal (Giorgianni, 1995: 200-215).

La llegada de Carlos a Messina el día 21 de octubre se relacionó con el surgimiento de la Constelación de Orión, prototipo del héroe militar, y la entrada del sol en el signo de Escorpión, bajo cuya protección se hallaba Messina. De este modo, por la Guerra de Túnez, Mesina y Carlos V aparecían unidos astronómicamente (Giorgianni, 1995: 200-216). Ese mismo día la ciudad de Mesina entregó al emperador 10.000 escudos de oro en dos bandejas de plata (Madonna, 2000: 130) junto con un cuadro de Polidoro da Caravaggio. ${ }^{5}$

El lunes, día de Todos los Santos, volvió el emperador a la catedral para nombrar caballeros de la Orden del Toisón a Ferrante de Gonzaga, nuevo virrey de Sicilia, y al Caballero Mayor. Por la tarde fue al monasterio de Santo Helia, de la orden de San Francisco de Paula, donde asistió al oficio de difuntos. A la mañana siguiente, 2 de noviembre y día de los Difuntos, oyó misa en el monasterio de Santo Helia, para regresar de nuevo al Palacio Real, saliendo de la ciudad por la puerta de Santa María del Pilerio hacia el puerto a través del puente de la Dogana, donde pudo contemplar el programa iconográfico del arco de triunfo allí ubicado, que estaba presidido por Neptuno y otras divinidades marinas, que le auguraban un feliz viaje hacia la península italiana.

Su Majestad embarcó en una galera de Messina junto a otros importantes personajes de la ciudad y del reino, realizando la travesía hasta la playa de Calabria para continuar su viaje triunfal hasta el norte, que va a finalizar en la ciudad de Luca (Alibrando, 1535: 512-513). La partida del emperador de la isla de Trinacria estuvo acompañada del tronar de la artillería, el sonar de las trombas, los bífalos, las trompetas y la multitud del pueblo, que gritaba "Carlo, Carlo, César, César, Imperio, Imperio».

5. Agati (2009: 147) señala que al emperador se le entregaron además de los 10.000 escudos de oro las telas dibujadas por Polidoro da Caravaggio para las decoraciones efímeras junto con los textos en prosa y en verso de Francesco Maurolico. 


\section{BIBLIOGRAFÍA}

Agati, S. [2009], Carlo V e la Sicilia. Tra guerre, rivolte, fede e ragion di Stato, Catania, Giuseppe Maimone Editore.

Alibrando, N.G. [1535]. Il triompho il qual fece Messina nella intrata del imperator Carlo $V$..., Impresa in Messina, per Petruccio Spira, 1535. En Gallo, C.D. [1758]. Annali della cittá di Messina, capitale del Regno di Sicilia..., vol. 2, Messina, per Francesco Gaipa Regio impresore, 1758, 500-513.

Auria, V. [1690]. La giostra. Discorso historico, sopra l'origine (...), Palermo.

CAPRARO, M. [2007-2008]. «21 ottobre 1535: l'ingresso di Carlo V a Messina", Lexicon, 5-6, 95-102.

Castaldo, V. [1930]. «Il viaggio di Carlo V in Sicilia (1535) secondo una cronaca manoscritta napolitana", en Archivio Storico per la Sicilia Orientale, fasc. I, vol. 25 (1929), Catania.

CAstris, P. L. [2001]. Polidoro da Caravaggio: l'opera completa, Napoli, Electa.

Chastel, A. [1975], "Les entrées de Charles Quint en Italie», en Les Fêtes de la Renaissance. II. Fètes et cérémonies au temps de Charles Quint, Paris, Éditions du Centre National de la Recherche Scientifique, 1975, 197-206.

Checa Cremades, F. [1987]. Carlos V y la imagen del héroe en el Renacimiento, Madrid, Taurus.

Fagiolo, M., Madonna, M. L. [1981]. Il Teatro del Sole. La rifondazione di Palermo nel Cinquecento e l'idea della città barocca, Roma, Officina Edizioni.

Fede, M. S. [2005-2006], «La festa barocca a Palermo: città, architetture, istituzioni», Espacio, Tiempo y Forma, serie VII, Historia del Arte, 18-19.

Giorgianni, G. [1995]. La festa della Madonna Assunta a Messina, Messina, Società Mesinesse si Storia Patria.

Hittorff, J. I., Zanth, L. [1835]. Architecture moderne de la Sicile, Paris.
LA Monica, M. [2007]. Il monumento a Filippo $V$ a Palermo. Stile e iconografia, Palermo, Pitti Edizioni.

LigRestI, D. [2006]. "Sicilia aperta (secoli XV-XVII) di uomini e idee», en Quaderni Mediterranea, vol. 3.

Madonna, M. L. [2000]. "El viaje de Carlos V por Italia después de Túnez: el triunfo clásico y el plan de reconstrucción de las ciudades", en La fiesta en la Europa de Carlos V, Catálogo de la Exposición, Sevilla, Madrid, Sociedad Estatal para la Conmemoración de los Centenarios de Felipe II y Carlos V.

Mazzì, A. (ed.) [1989]. Processioni di Palermo sacre e profane, en Opuscoli del Marchese del Villabianca, collana diretta da S. Di Matteo, Palermo.

Mínguez, V., González Tornel, P., Chiva, J., Rodríguez Moya, I. [2014], La fiesta barroca. Los Reinos de Nápoles y Sicilia (15351713), Castelló, Universitat Jaume I.

Morales Folguera, J. M. [2014], "Las entradas triunfales de Carlos V en Italia", en Diálogos de Arte. Homenaje al profesor Domingo Sánchez-Mesa Martín, Granada, Universidad de Granada, 327-342.

Nobile, M. R., Scaduto, F. [2005-2006]. «Architettura e magnificenza nella Palermo del primo Cinquecento: il prospetto denominato di Santa Eulalia dei Catalani», Espacio, Tiempo y Forma, t. 18-19.

Palmeri, N. [1856]. Somma della storia di Sicilia, Palermo, G. Meli.

Santa Cruz, A. [1922], Crónica del Emperador Carlos V, Madrid, Real Academia de la Historia.

Viseglia, M. A. (2001a). "Il viaggio cerimoniale di Carlo V dopo Tunisi", in Dimensioni e problemi della ricerca storica, Rivista del Dipartimento di Storia Moderna e Contemporanea dell'Università di Roma La Sapienza, 2, 5-50.

Viseglia, M. A. [2001b]. "Il viaggio cerimoniale di Carlo V dopo Tunisi", Carlos Vy la quiebra del humanismo político en Europa (1530-1558), J. Martínez Millán (Coord.), Madrid, vol. 2, 101-108. 
